\title{
Design Multi Input Automatic Identifier System Class B for Indonesian Fishery
}

\author{
A Sumarudin ${ }^{1 *}$ Willy Permana Putra ${ }^{1}$, Ahmad Rifai ${ }^{1}$, Agfianto Eko Putra ${ }^{2}$ \\ ${ }^{1}$ Department of Informatics, Politeknik Negeri Indramayu Indonesia. \\ ${ }^{2}$ Department of Computer Science, Universitas Gadja Mada, Indonesia \\ *Corresponding author email: shumaru@polindra.ac.id
}

\begin{abstract}
The need for technology that can help Indonesian fishermen is needed to improve fishing yields. Based on BPS data Indonesian fishermen dropped from 1,7 million to 64 thousand in 2013. This is due to several factors, including unfavourable professions for fishermen. This is insufficient fishing equipment for fishing. One of them is the need for navigation tools that are easily understood by traditional fishermen and in accordance with the needs in fishing. We propose the design of Class B's Automatic Identifier System (AIS) to help fishermen navigate and find fish points. In this system we also propose determining the point of fish based on information from fishermen who are collectively collected by the fishermen. With this design it is hoped that the fish point can be shared with other fishermen. The result this design, it is expected to be able to assist fishermen in navigating using AIS so that fishermen security with AIS system with multiple sensor can be improved find the point of fish obtained from sending data from several fishermen and collect data weather for safety.
\end{abstract}

Keywords: AIS, Fishery, Fish Point, navigation, safety Fishermen, Sensor

\section{Introduction}

The need for technology that can help Indonesian fishermen is needed to improve fishing yields. Based on BPS data Indonesian fishermen dropped from 1.7 million to 64 thousand in 2013. This is due to several factors, including unfavorable professions for fishermen. This is insufficient fishing equipment for fishing. One of them is the need for navigation tools that are easily understood by traditional fishermen and in accordance with the needs in fishing.

Shipping security is the main thing in a cruise with a level of awareness by using identification from the boat, tracker and monitoring (Chang, 2004). Based on safety of life at 
sea (SOLAS) at vessek meliputi ship reporting system, vessel traffic system, global maritime distress and safety system, electronic chart display and information system, and automatic identification system (Chang, 2004). The vessel information needed includes position, flag, type, etc. (Yang and Jeong, 2016) AIS integrated with sentinel-1 (Yang and Jeong, 2016). Some applications use wireless communication using frequency $2.4 \mathrm{GHz}$ (Zainuddin et al., 2018). Development fishermen communication use lora with the maximum distance $3.73 \mathrm{Km}$ (Fuada et al., 2019; Adiono et al., 2019) in previous studies had been carried out using a LORA-based small vessel multi gateway (Sumarudin et al., 2019) the use of ice is also used to avoid collision vessels on the beach (Tetreault, 2005). Boat detection uses combining AIS data and ALOS images to make boat detection based on satellite imagery (Watagawa et al., 2012).

In this paper, we propose the design of Class B's Automatic Identifier System (AIS) to help fishermen navigate and find fish points. In this system we also propose determining the point of fish based on information from fishermen who are collectively collected by the fishermen. With this design it is hoped that the fish point can be shared with other fishermen.

\section{Design System Propose}

Based on design, we propose design automatic identifier system utilize multi input.

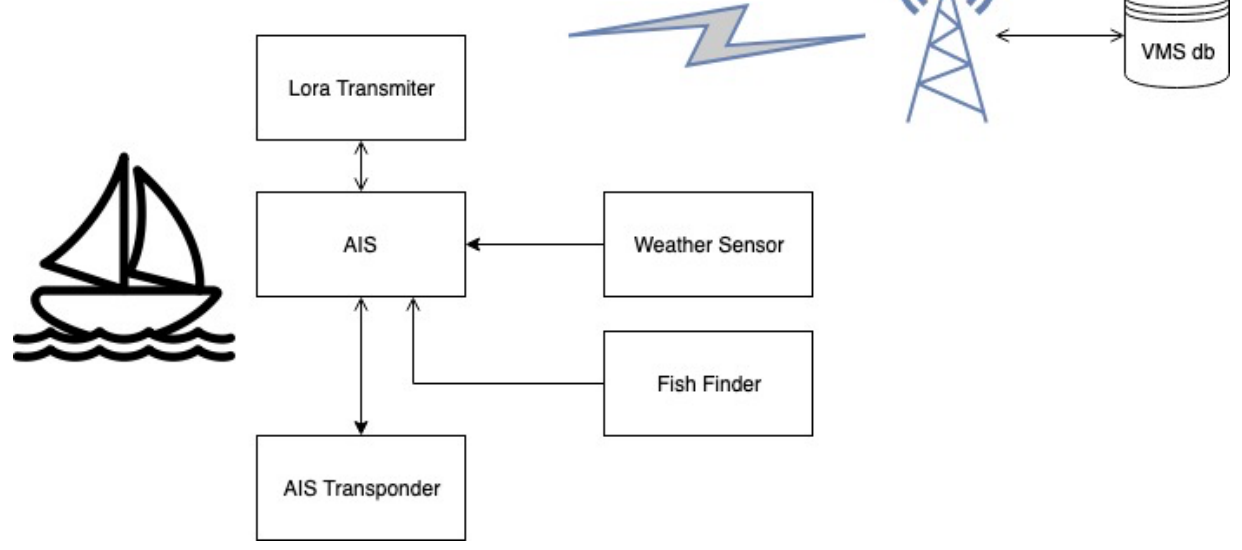

Figure 1: Design System AIS for Fishery

This design consists of the AIS system using raspberry pi. In the system installed with open plotter to navigate the system using AIS transponder with class B using ray marine. For the needs of weather data and fish points using data sent using a LORA transmitter sent to the gateway. 


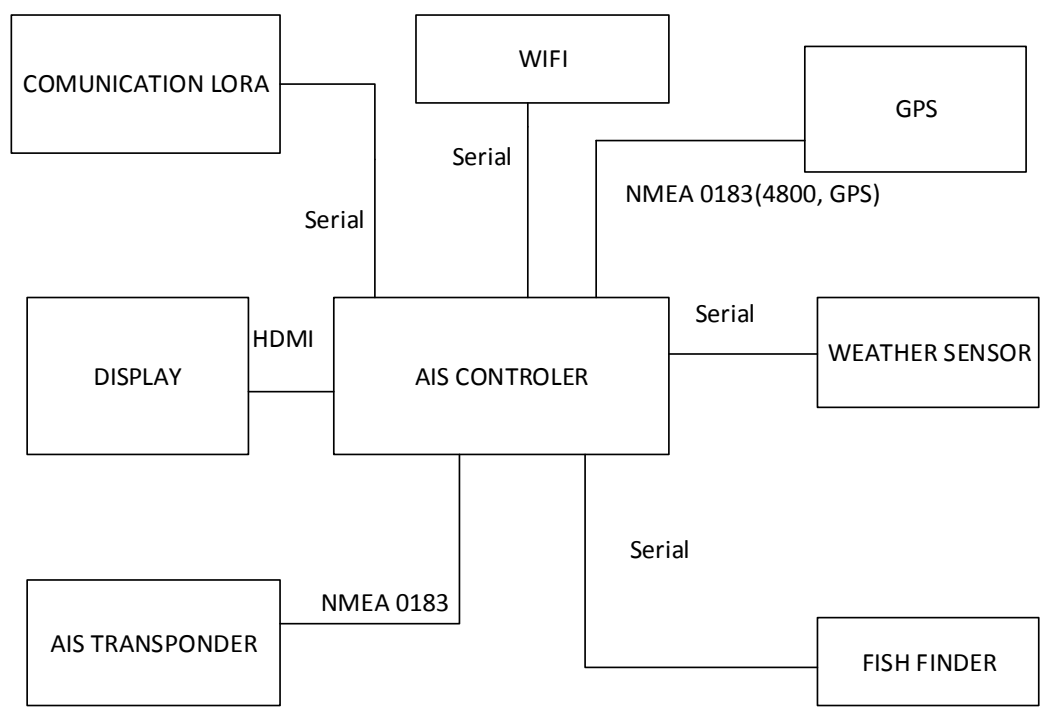

Figure 2 : Block System AIS

Based on the picture above, the system consists of an AIS controller which is an integrated system for multi-input developed. In this system we can add several inputs using an open plotterbased AIS controler. Open plotter is an open source that combines several features for the navigation needs of a ship. In the system that we built using AIS class B for AIS navigation and open plotter as a controller to combine the data that is run on the system. The system in Figure 2 shows the system for fishermen per year, the system helps navigation of fishermen when they are sailing. From this system it will be sent to the VMS using an AIS transponder that is received on the AIS side receiver mounted on the beach side. For fish point shipping needs will be stored in the AIS Controler and when receiving LORA signals / other communication systems will be sent and received data updates. For the needs of fishermen who will sail long distances, they will use satellite-based data communication. In Table 1, shown the features of the open plot used in this system.

Table 1. Feature AIS

\begin{tabular}{cll}
\hline No & \multicolumn{1}{c}{ Feature } & \multicolumn{1}{c}{ Function } \\
\hline 1 & OpenCPN & Software navigation for vessel \\
2 & SDR-AIS & AIS trasponder based on SDR \\
3 & NMEA 0183 & Receiver NMEA Data with serial communication \\
4 & Wifi Acces Point & Cnncetion NMEA And signal K with other device \\
5 & Digital and analog sensor & Read sensor digital and analog \\
6 & I2C Wire & Read Sensor With I2C Communication \\
7 & Dashboard & Visible data and instrument panel \\
\hline
\end{tabular}


Whereas the fish finder uses $200 \mathrm{KHz}$ with maximum, 839 feat seawater readings. For realtime weather readings on a boat using the weather sensor initial sensor input to calculate the wind rotation. And use I2C wire for temperature, humidity and pressure. For wind direction using analog sensors, to determine rainfaal using digital sensors (Kuncoro et al., 2020).

\section{Design Implementation}

Based on the system design above, we use SDR-based AIS transponders and Raspberry Pi as a controler (Seen Figure 3).

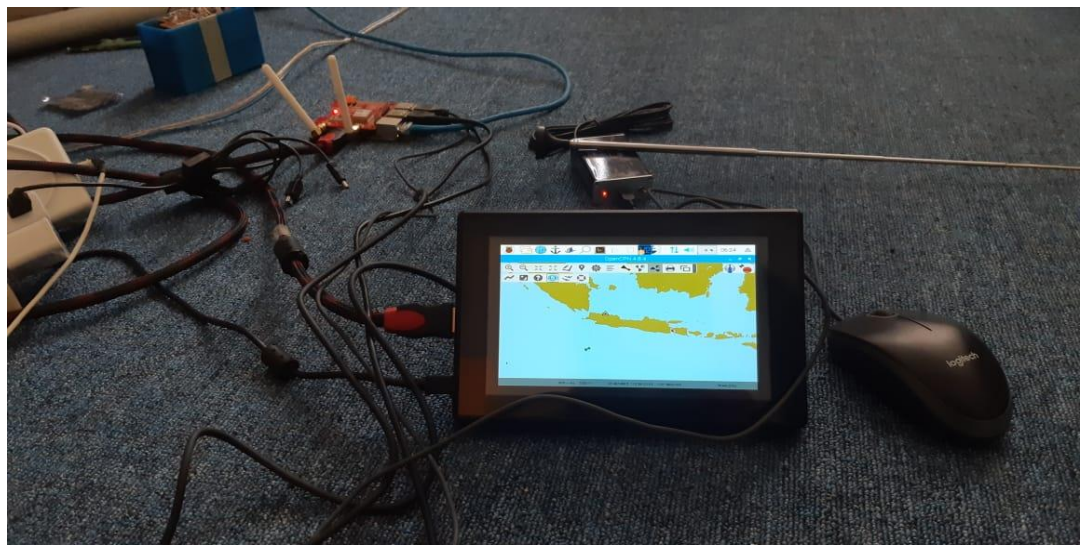

Figure 3: System Implementation

From the implementation, the system reads the ice signals from the boats around. The data is available in the system and provides information for Indonesian traditional fishermen to use (See Figure 4).

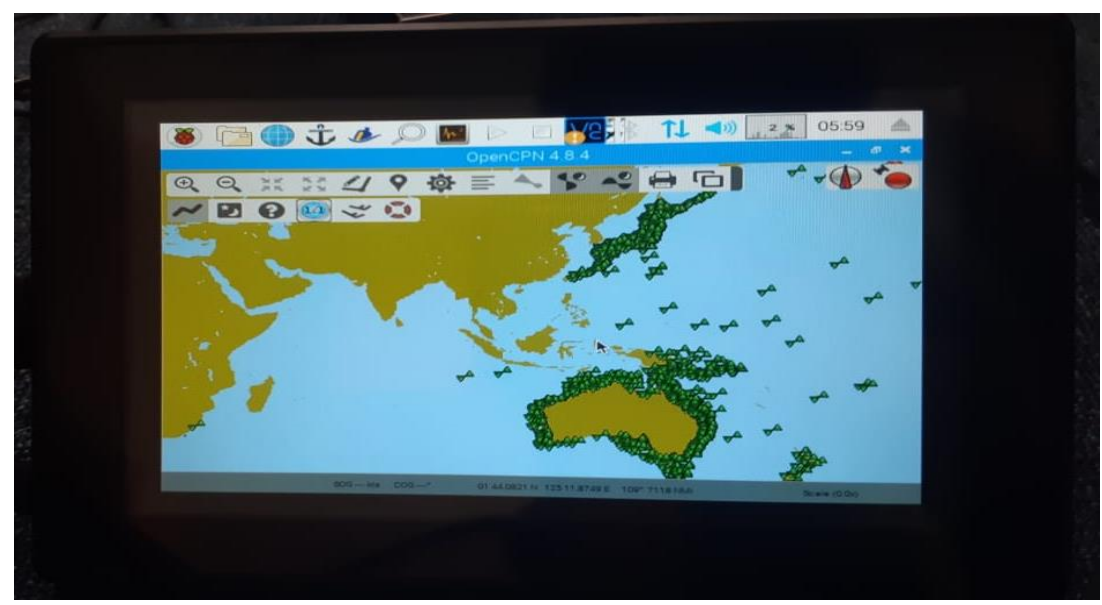

Figure 4: Display of AIS system 
To provide a fish point on the VMS system, we use a fishfinder and the results of our detection are sent to the vms system. In Figure 5, it appears that the fish detection process uses a fish finder.

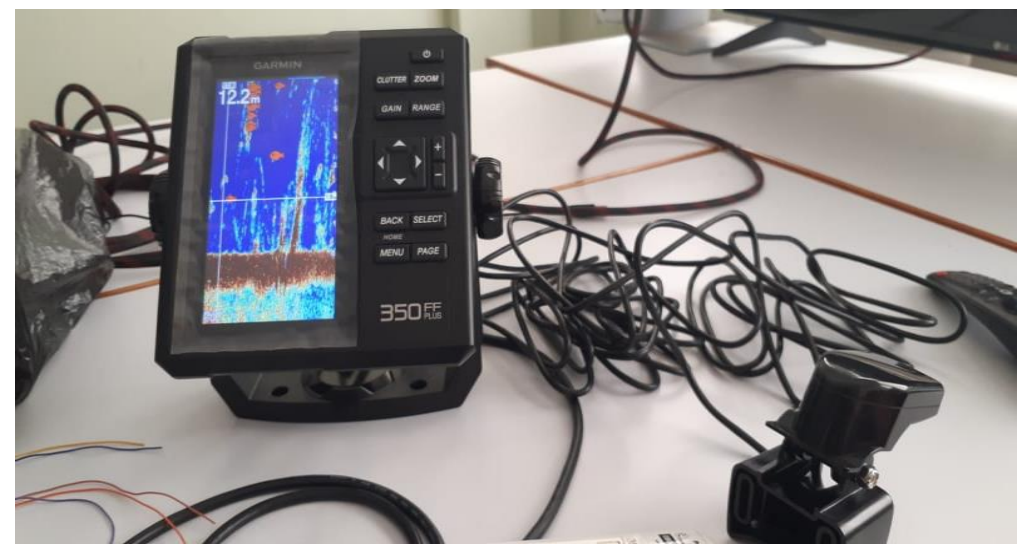

Figure 5: Fish finder

For the needs of fishermen who go further to sea can use communication satellites. For monitoring systems, a vessel management system (VMS) was built for data analysis needs. The results of this data analysis will be informed to fishermen using mobile apps (See Figure 6).

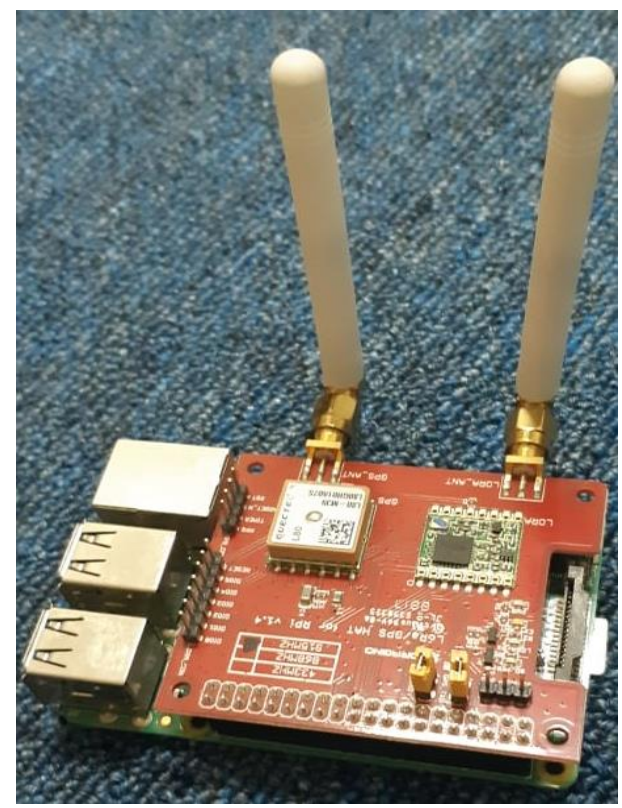

Figure 6: AIS System 
From this design, it is expected to be able to assist fishermen in navigating using AIS so that fishermen security can be improved and find the point of fish obtained from sending data from several fishermen. For very long range communication fishermen can use communication satellites or TDM/TDMA based on IP with latency $650 \mathrm{~ms}-1000 \mathrm{~ms}$ and bandwidth $2.4 \mathrm{Kbps}-$ 2 Mbps.

Vessel monitoring systems, a vessel management system (VMS) was built for data analysis needs. This system uses a web base application that can be accessed by fishermen and government agencies to provide information about the existence of fish and the distribution of fishermen who are doing fishing.

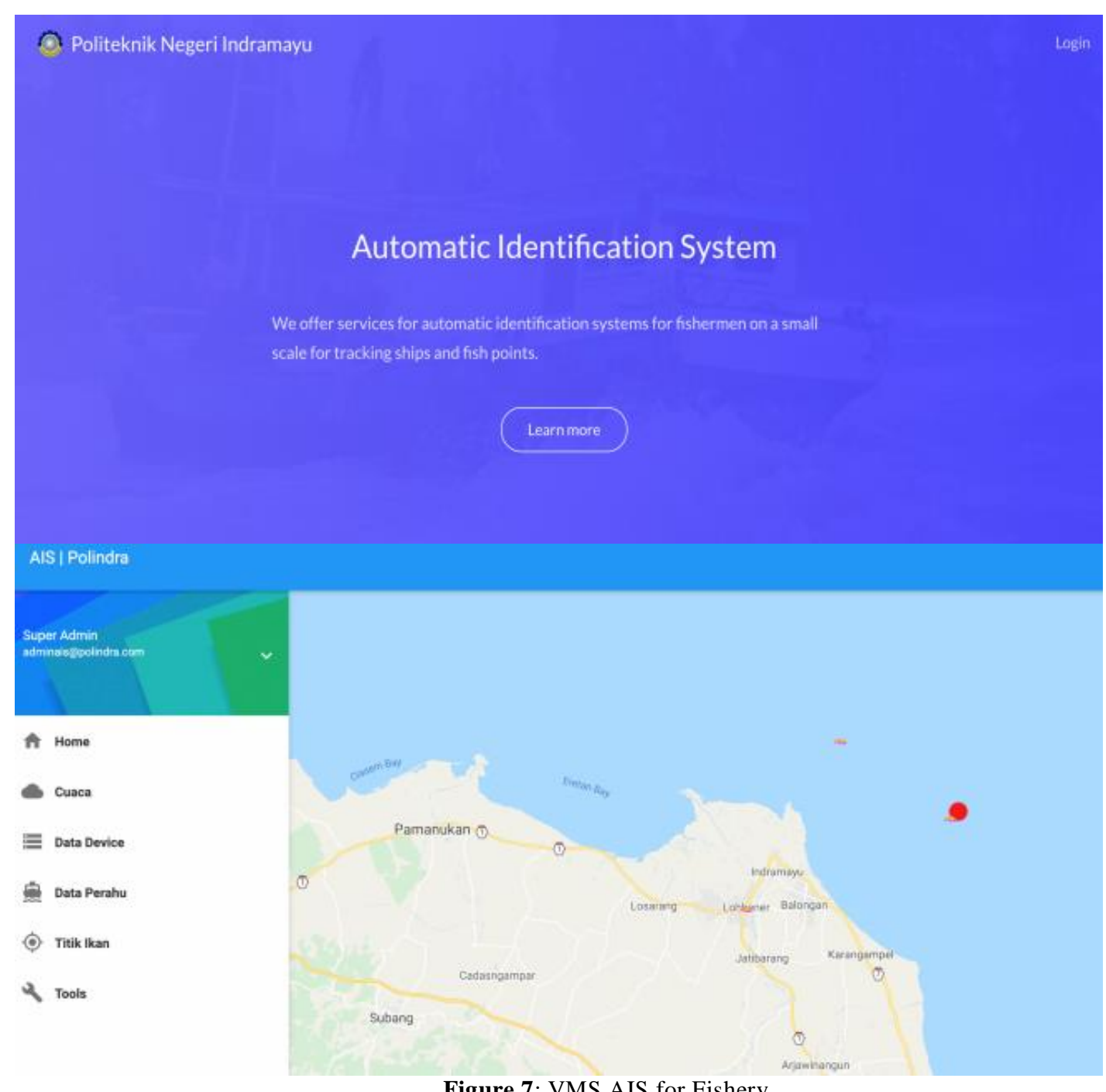

Figure 7: VMS AIS for Fishery 


\section{Conclusion}

The result this design, it is expected to be able to assist fishermen in navigating using AIS so that fishermen security with AIS system with multiple sensor can be improved find the point of fish obtained from sending data from several fishermen and collect data weather for safety.

\section{References}

Adiono, T., Dawani, F., Adinugraha, E., Rifai, A., Arijal, M., Fuada, S., \& Samhany, H. A. (2018, October). Development of long-range communication system for fishermen: an initial study. In 2018 International Conference on ICT for Rural Development (IC-ICTRuDev) (pp. 12-17). IEEE.

Chang, S. J. (2003, October). Vessel identification and monitoring systems for maritime security. In IEEE 37th Annual 2003 International Carnahan Conference onSecurity Technology, 2003. Proceedings. (pp. 66-70). IEEE.

Dawani, F., Fuada, S., Anindya, S. F., Rifai, A., Adinugraha, E., Purwanda, I. G., \& Adiono, T. (2018). Prototype of Long-Range Radio Communication for e-Nelayan Devices using LoRaWAN. Jurnal Infotel, 10(4), 202-209.

Kuncoro, A. H., Mellyanawaty, M., Sambas, A., Maulana, D. S., Subiyanto and Mamat, M. (2020). Air Quality Monitoring System in the City of Tasikmalaya based on the Internet of Things (IoT). Journal of Advances Research in Dynamical \& Control Systems, 12(2), 2473-2479.

Sumarudin, A., Putra, W. P., Rifai, A., \& Putra, A. E. (2020, May). Small Vessel Tracking Based on Multi Gateway LORA for Indramayu Traditional Fishery. In IOP Conference Series: Materials Science and Engineering (Vol. 850, No. 1, p. 012035). IOP Publishing.

Tetreault, B. J. (2005, September). Use of the Automatic Identification System (AIS) for maritime domain awareness (MDA). In Proceedings of Oceans 2005 Mts/leee (pp. 1590-1594). IEEE.

Watagawa, M., Kobayashi, E., \& Wakabayashi, N. (2012, May). Monitoring of vessel traffic using AIS data and ALOS satellite image. In 2012 Oceans-Yeosu (pp. 1-4). IEEE.

Yang, C. S., \& Jeong, J. (2016, July). Integrated ship monitoring system for realtime maritime surveillance. In 2016 IEEE International Geoscience and Remote Sensing Symposium (IGARSS) (pp. 4046-4047). IEEE.

Zainuddin, Z., \& Nantan, Y. (2017, October). Applying maritime wireless communication to support vessel monitoring. In 2017 4th International Conference on Information Technology, Computer, and Electrical Engineering (ICITACEE) (pp. 158-161). IEEE. 